\title{
LÕIMITUD AINE- JA KEELEÕPPE METOODIKAST VENE ÕPPEKEELEGA KOOLIS
}

\author{
Helena Metslang, Mare Kitsnik ja Ingrid Krall \\ Tallinna Ülikool
}

\begin{abstract}
Kokkuvõte. Aastatel 2007-2012 toimus vene õppekeelega gümnaasiumide üleminek eestikeelsele aineõppele. Tallinna Ülikooli 2012. aasta sügisel koolides korraldatud uuring „Kakskeelne õpe vene õppekeelega koolis” kinnitas, et eestikeelne aineõpe on tõepoolest käima läinud ja kiirelt arenemas. Artikkel käsitleb lähemalt mõningaid õppe tulemuslikkuse faktoreid, mida uuringu käigus eestikeelses aineõppes ja seda toetavate eesti keele kui teise keele tundide juures analüüsisime. Eri sihtrühmade anketeerimise, fookusgrupiintervjuude ning ligi 80 tunnivaatluse põhjal teeme järeldusi eestikeelse õppe olukorra ja arenguvõimaluste kohta, keskendudes metoodika aspektile. Uuringu teoreetilisteks lähtekohtadeks on LAK-õpe (lõimitud aine- ja keeleõpe) ning aktiivõppe ja kommunikatiivõppe metoodika. Enamik artiklis vaadeldud metoodilisi jooni on olulised ka läbivalt eestikeelse hariduse kontekstis - nii keeleõppes kui ka aineõppes. Hoolimata vene õppekeelega koolide õpilaste arvu vähenemisest on kasulik jätkuvalt toetada haridustöötajate pädevuste arengut nendes metoodikavaldkondades - eriti arvestades õpilaskonna kultuurilist mitmekesistumist eesti õppekeelega koolis.
\end{abstract}

Märksõnad: eesti keel, teine keel, rahvusvähemuste haridus, keeleõppe metoodika, lõimitud aine- ja keeleõpe

DOI: http://dx.doi.org/10.12697/jeful.2014.5.3.04

\section{Sissejuhatus}

Alates 2011. aastast õpivad kõik 10. klassi astuvad eesti keelt teise keelena kõnelevad noored gümnaasiumis $60 \%$ ulatuses aineid eesti keeles. Riiklikes õppekavades soovitatakse keeleõppes kasutada LAKõppe metoodikat (ingl content and language integrated learning, CLIL). LAK-õppe metoodika on lähenemine, kus mistahes kooliastmes või ka lasteaias õpitakse üheaegselt nii õppeainet, nt ajalugu, kui ka keelt. LAK-õppe aineõpetaja on mingil määral ka keeleõpetaja rollis ning keeleõpetaja toetab aineõpet spetsiaalse sõnavara ja keelendite õpetusega (Mehisto jt 2010: 13, vt ka allpool). LAK-õppe tulemuslikkust kinnitavad rahvusvahelised uuringud ja parimad praktikad, mille hulka 
võib lugeda ka Eesti keelekümbluse kogemust (nt Genesee 2003: 17). Metoodika põhimõttekindla kasutamise korral arenevad edukalt nii õpilaste aine- kui ka keeleteadmised ning tihti LAK-õppe õpilased isegi edestavad eakaaslasi aineteadmistes (vt Eesti keelekümbluse mõju uuringuid Sau-Ek jt 2008, 2011 ja Kukk jt 2009 ning ülevaadet teiste riikide uuringutest García 2009, Lindholm-Leary ja Borsato 2006 ja Mehisto 2012: 83-84, 91-95).

LAK-õpe on kompleksne õppeprogramm, mis hõlmab lisaks metoodikale ka muid aspekte: juhtimist, spetsiaalseid õppevahendeid, eesmärkide, mõjude ja tulemuste täpset kavandamist, kommunikatsiooni eri sidusrühmadega jne. Näide niisugusest komplekssest kavandamisest on tulemusjuhtimise meetodil põhinev raamdokument „Keelekümblusprojekt" (1998, vt ka Mehisto 2012: 20-23). Selle lähenemise sihipärane kasutuselevõtt on vaevanõudev ja koolide tööd sügavuti muutev tegevus. Samal ajal võib LAK-õppe poolik rakendamine, kui õpe ei toimu läbimõeldud ja hästi juhitud programmi järgi, õpilastele isegi kahju tuua (Genesee ja Lindholm-Leary 2012, vt arutelu Hong Kongi riikliku keelekümblusprogrammi kriitika üle Mehisto 2012: 99-101).

Eesti riik on astunud ulatuslikke samme teiskeelse õppe arendamiseks. Mitmete õppeainete jaoks on välja antud tugiõppematerjale, õpetajaid on ulatuslikult koolitatud ning on toimunud põhjalikud arutelud koolijuhtidega, samuti on läbi viidud uuringuid (vt allpool). Ülemineku käigus toetati koole ka rahaliselt. Lisaks on juba 2000. aastast madalamatel õppeastmetel edukalt rakendatud keelekümblusprogrammi. Lõimitud aine- ja keeleõppe programmi pakkumise muudab vene õppekeelega koolides keeruliseks see, et õpilaste arv on kahanemas ning paljudes neist koolidest astub igal aastal 10. klassi vaid paarkümmend õpilast. Kuigi mitte-emakeeles õppimine nõuab õpilastelt rohkem aega ja pingutust, ei tehta gümnaasiumi õppekavas K2-õppuritele nõuete osas praegu mööndusi - see on väljakutse nii õpilastele kui ka õpetajatele-juhtkondadele.

Artiklis käsitleme lähemalt mõningaid Tallinna Ülikooli eesti keele ja kultuuri instituudi poolt läbi viidud uuringu „Kakskeelne õpe vene õppekeelega koolis" (Metslang jt 2013) põhitulemusi. Anname ülevaate teiskeelse õppe tulemuslikkuse tagamise tegevustest ja faktoritest. Keskendume kahele valdkonnale: teiskeelsele aineõppele ning eesti keele kui teise keele tundidele. Arutleme järgmiste küsimuste üle:

- Kas õpilaste reaalne eesti keele oskuse tase võimaldab neil gümnaasiumi aineõppega toime tulla? 
- Mil määral ja mil viisil kasutatakse eestikeelsetes ainetundides ja eesti keele kui teise keele tundides aktiivset õppijakeskset ning traditsioonilist õpetajakeskset metoodikat?

- Kuidas toimub aine- ja keeleõppe lõimimine?

- Missugused on teiskeelse õppe ja keeleõppe raskuskohad ning mis neid põhjustab?

Artikkel koosneb neljast jaotisest. Sissejuhatav osa jätkub ülevaatega varasematest analüüsidest rahvusvahelises ja Eesti kontekstis ning uuringu valimi ja metoodika kirjeldusega. Järgnevad eestikeelse aineõppe olukorda käsitlev peatükk ning edasi vaadeldakse, kuidas eesti keele tunnid aitavad kaasa õpilaste toimetulekule eestikeelses õppes. Viimases osas võtame kokku peamised metoodikaga seotud faktorid, mis eestikeelse aineõppe tulemuslikkust mõjutavad.

\subsection{Kakskeelse õppe programmid ja nende uurimine}

Kvaliteetsete haridusprogrammide ja kitsamalt kakskeelsete programmide edufaktoriteks peetakse positiivset õpikeskkonda, õppeainete jm õppetöö aspektide lõimingut, teoreetiliselt põhjendatud ja parimatele praktikatele tuginevat kakskeelse õppe programmi, õppekava, mis on seotud õpilaste elu, huvide ja probleemidega ning on parasjagu raske, kuid mitte ülejõukäiv, koolitöötajaid ja õpilasi ühendavate ühiste eesmärkide olemasolu ning õpetuse sisu selget fookust (Lindholm-Leary ja Borsato 2006: 181, 187-188, Berman jt 1995, Corallo ja McDonald 2002 ja Gándara 1995 jpt).

Vähemuskeeli kõnelevate õpilaste hariduses eristatakse programme, mille eesmärk on mitte-emakeelsete õpilaste võimalikult kiire liitumine nende jaoks teises keeles, üldjuhul enamuse keeles toimuva õppetööga ning programmideks, mille puhul on suurem rõhk kakskeelsuse arendamisel. Muudes riikides läbi viidud analüüsid on leidnud, et viimane lähenemine on andnud paremaid õpitulemusi (Lindholm-Leary ja Borsato 2006). Kuigi Eesti vene õppekeelega koolides alustatakse eestikeelse õppega maailma mõistes tavatult hilja (peame silmas kohustuslikku üleminekut gümnaasiumis, mitte keelekümblust), võib siiski ka seda õppeprogrammi lugeda väga tugevalt sellesse teise, kakskeelsust tähtsustavasse rühma kuuluvaks: riiklikus õppekavas (RÕK) on eriti just algkoolis ja põhikoolis rõhk vene emakeele õppel. 
Kakskeelses õppes osalevate õpilaste akadeemilist edukust on maailmas palju uuritud. Levinud on erinevate kakskeelse hariduse programmide tulemuslikkuse mõõtmine ja võrdlemine ükskeelse hariduse programmidega ja omavahel (vt nt sissejuhatus). Eesti praktikas on olnud rõhk sotsioloogilistel meetoditel ning vaadeldud on õpilaste toimetulekut ja õpitulemusi teiskeelses õppes ning osapoolte hinnanguid üleminekule, keelekümblusele ja eestikeelse õppe vajalikkusele (Integratsioonimonitooring 2011, Kello jt 2011, Masso ja Kello 2010, Mehisto 2009, Sau-Ek jt 2011 ja Rannut 2005). Vähem on tegeldud keeleõppe metoodika üksikasjaliku uurimisega (vt Kello jt 2011, Mehisto 2009 ja 2012 ja Sau-Ek jt 2011). Vaadeldud on ka keeleõppe motivatsiooni seoses keelekeskkonnaga ja üleminekuga eestikeelsele õppele (vt Klaas-Lang jt 2014, Rannut 2005, Peedisson 2012 ja Rozova 2012). Vähe on põhjalikumaid uuringuid haridusprogrammide ja teise keele omandamise seostest (kuid vt nt Rannut 2005).

Siinkohal on vajalik selgitada mõningaid artiklis kasutatud termineid. Vene õppekeelega kooli all peame silmas koole, kus oluline osa õppetööst toimub vene keeles. Kuigi gümnaasiumiastmes toimub enamik õppetööst eesti keeles, aitab see termin eristada neid koole valdavalt eesti emakeelega õpilaskonnaga koolidest. Neid (vene õppekeelega koolide) klasse, kus põhikoolis ei õpetatud keelekümblusprogrammi järgi, nimetame tavaklassideks.

\subsection{Valim ja metoodika}

Uuringus osalevate koolide leidmisel taotlesime võimalikult tasakaalustatud valimit, mis esindaks eri regioonide vene õppekeelega koole proportsionaalselt. Uuringu põhivalim sisaldas 8 kooli, kus andmete kogumine viidi läbi täismahus. Nende seas oli 4 Tallinna ja 3 Ida-Virumaa kooli ning 1 muu Eesti kool. Viimaste aastate põhikooli eesti keele kui teise keele lõpueksami järgi jagunesid uuritavad koolid tugevate, keskmiste ja nõrkade tulemustega koolideks (vastavalt 2, 4 ja 2 kooli). Esindatud oli 2 varase ja 2 hiliskeelekümblusega kooli (neis koolides uurisime nii keelekümblustaustaga kui ka tavaklasside õpilasi).

Kasutame järgnevas analüüsis allikana osa 2012. aasta septembrisoktoobris koolides kogutud materjalist:

- 11.-12. klassi õpilaste e-Formulari ankeedid ja fookusgrupiintervjuud;

- 9. -12. klassi eesti keele kui teise keele õpetajate e-Formulari ankeedid ja fookusgrupiintervjuud; 
- 9.-12. klassis eesti keeles aineid õpetavate õpetajate e-Formulari ankeedid ja fookusgrupiintervjuud;

- eesti keele tundide ja eestikeelsete ainetundide vaatlused 9.-12. klassides.

Tunnivaatluste ja fookusgrupiintervjuude tulemused aitasid ankeetidega kogutud (sageli vastukäivat) infot hinnata ja adekvaatsemalt tõlgendada (vt jaotised 2 ja 3 ).

Artikli aluseks oleva uuringu ettevalmistus hõlmas koolide valimi koostamist, konsulteerimist LAK-õppe ekspertidega (Peeter Mehisto ja Kai Võlli), küsimustike, intervjuuraamide ja tunnivaatluslehtede loomist, piloteerimist ja täiendamist, õpetajate anketeerimist, koolikülastusi (mille käigus vaadeldi tunde, intervjueeriti eri sihtrühmi ja anketeeriti õpilasi), fookusgrupiintervjuude läbiviimist, intervjuude litereerimist, ankeetide sisestamist ning andmeanalüüsi. Tabel 1 annab ülevaate andmetest, mida on siinse artikli juures arvesse võetud.

Tabel 1. Andmekogumisetapil kaheksas põhivalimikoolis kogutud andmete maht $^{1}$

\begin{tabular}{l|l|c|c|c} 
Meetod & Ühik & Ópilased & $\begin{array}{c}\text { Eestikeel- } \\
\text { sete ainete } \\
\text { opetajad }\end{array}$ & $\begin{array}{c}\text { Eesti keele } \\
\text { kui teise keele } \\
\text { opetajad }\end{array}$ \\
\hline ankeedid & vastajate arv & 561 & 180 & 118 \\
\hline $\begin{array}{l}\text { fookusgrupi- } \\
\text { intervjuud }\end{array}$ & $\begin{array}{l}\text { intervjuude arv / } \\
\text { osalejate arv (tk/ } \\
\text { neis osalejate arv }\end{array}$ & $3 / 16$ & $4 / 15$ & $3 / 13$ \\
\hline tunnivaatlused & $\begin{array}{l}\text { põhivalimikoolis } \\
\text { vaadeldud tunde }\end{array}$ & & 32 & 36
\end{tabular}

Lisaks põhivalimi koolidele anketeeriti eesti keele kui teise keele õpetajaid ja eesti keeles aineid õpetavaid õpetajaid üle Eesti. Fookusgrupiintervjuud viis läbi moderaator koos abimoderaatoriga, kelleks olid projekti töörühma liikmed. Intervjuud kestsid 45-90 minutit. Põhivalimi koolides toimunud fookusgruppide kõrval kasutame artiklis ka pilootkooli fookusgruppides kogutud materjali (viisime läbi fookusgrupiintervjuud nii õpilaste, keele- kui ka aineõpetajatega, kokku 17 osalejat). Õpilaste ankeet ja fookusgrupid olid venekeelsed, et vältida

1 Kuna mõne kooli õpetajatel ei olnud võimalik osaleda suuremal fookusgrupiintervjuul, viisime nendega läbi paarisintervjuud ( 2 paarisintervjuud eesti keeles ainet õpetavate õpetajatega, 1 eesti keele kui teise keele õpetajatega). 
vähesest keeleoskusest tuleneda võivaid vääritimõistmisi. Keele- ja aineõpetajate ankeedid ja fookusgrupid olid eestikeelsed. Kolm keeletunnivaatlust toimus keelekümblustaustaga klassides ja ülejäänud tavaklassides. Ainetunnivaatlustest olid 3 tundi varase keelekümblustaustaga, 6 hiliskeelekümblustaustaga klassis ja 27 tavaklassis. Koole oli ette informeeritud, mis päeval vaatleja tunde külastab, kuid neid polnud teavitatud sellest, millised tunnid vaatleja vastava päeva tunniplaanist valib. Analüüsis võtsime arvesse ka pilootkoolis vaadeldud tunde (4 keeletundi ja 5 ainetundi).

Võtsime ankeetide koostamisel, tundide vaatlemisel ning kogutud andmete tõlgendamisel aluseks LAK-õppe käsiraamatus (Mehisto jt 2010) ning muus metoodikakirjanduses (nt Nunan 2004, Willis 1996 ja 2008 ja Krall jt 1997) esitatud põhimõtted. See lähenemine võimaldas eri uuringuosade käigus saadud andmeid võrrelda. Osa järgnevates jaotistes esitatud seisukohti põhineb ka artikli autorite praktikukogemusel keeleõpetajate ja -õppejõududena ning õppematerjalide autoritena.

\section{Eestikeelsete ainetundide metoodika ja keeletugi}

Eestikeelse aineõppe eesmärk on viia gümnaasiumilõpetajate eesti keele oskus tasemeni, mis võimaldaks neil olla täievolilised ja aktiivsed ühiskonnaliikmed, kes omavad nii elukestvas õppes, tööturul kui ka kõigis muudes elusfäärides samu valikuvõimalusi kui eesti keelt emakeelena kõnelejad. Et see ambitsioonikas eesmärk ka täidetud saaks, selleks on vaja kasutada ainetundides kvaliteetset õppemetoodikat, mille abil omandatakse korralikud aineteadmised ning areneb ka õppijate eesti keele oskus. Käesolevas jaotises vaatleme, millist metoodikat ja millise tõhususega eestikeelsetes ainetundides kasutatakse ning pöörame eraldi tähelepanu keeletoe andmisele ainetundides. Alustame üldiste arvamuste ja hinnangutega eestikeelsele õppele.

\subsection{Teiskeelse õppe põhjendatus ning õpilaste toimetulek selles: eri osapoolte hinnangud}

Umbes kolmveerand uuringus osalenud aineõpetajatest vastas ankeetküsitluses, et nende arvates on eestikeelne aineõpe gümnaasiumis mõttekas ja kasulik ning võimaldab saavutada häid õpitulemusi nii aines kui ka keeles. Peamise kasuna nimetati õpilaste eesti keele oskuse 
paranemist, mis tagab pärast kooli lõpetamist parema toimetuleku Eesti ühiskonnas. Samas ei pidanud tervelt veerand aineõpetajatest, kes ise eesti keeles õpetavad, eestikeelset aineõpet õpilastele kasulikuks ning koguni 39\% pedagoogidest eelistaks võimaluse korral oma ainet siiski vene keeles õpetada. Seega ei ole ka osa eestikeelsesse aineõppesse positiivselt suhtujatest teiskeelse õppe kasulikkuses päris veendunud. Vene emakeelega õpetajate puhul mõjutab vene keeles õpetamise soovi ka eesti keele oskus: mida paremini õpetajad eesti keelt oskavad, seda vähem nad soovivad oma ainet vene keeles õpetada.

Tunnivaatlustest ja õpilasankeedi tulemustest ilmnes, et ametlikult eestikeelne aineõpe toimub põhiosas tõepoolest eesti keeles. Külastatud eestikeelsetes tundides toetas vaatleja hinnangul õpilaste toimetulekut konstruktiivne tööatmosfäär. Õpilased leiavad, et aineõpetajad loovad tunnis pingevaba õhkkonna ja julgustavad neid tunnitegevuste käigus (vastava küsimuse vastusevariandid jah või pigem jah 59\% õpilasankeedile vastajate arvates). Seda kinnitasid ka ainetundide vaatlused. Lisaks vastas $65 \%$ õpilastest, et aineõpetajad aitavad ja toetavad õpilasi, kui need eesti keeles millestki aru ei saa (vt ka õpilaste abistamise võtteid keeletunnis jaotises 3.2.5).

Eesti keeles õpetamisel on aineõpetajate peamine mure seotud õpilaste ebaühtlase keeleoskustasemega. Endised keelekümblusklasside õpilased ning tugevamad ja motiveeritumad tavaklassiõpilased tulevad pedagoogide hinnangul eestikeelse aineõppega toime. Ülejäänutele on see liiga raske ning seetõttu kulub suur osa tunniaega sellele, et muuta materjal õpilastele teatud määralgi arusaadavaks. Vaid viiendik eestikeelsete ainete õpetajatest leidis, et nende õpetatavate klasside nõrgem pool tuleb nende aine õppimisega toime. Seda kinnitavad ka õpilased ise - ligikaudu pooled õpilasankeedile vastanud ei saa paljude eestikeelsete ainete tundides toimuvast enda sõnul peaaegu midagi aru. Õpilaste fookusgrupiintervjuudel väljendasid kõik osalejad arvamust, et nende jaoks oli üleminek eestikeelsele aineõppele gümnaasiumitasemel liiga järsk ja raske. Õpetajate arvamused peamiste probleemide kohta eestikeelses aineõppes on esitatud tabelis 2 . 
Tabel 2. Eestikeelses aineõppes enim raskusi tekitavad tegevused. Aineõpetajate ankeedivastused

\begin{tabular}{l|c} 
Probleemid eestikeelses aineõppes & Vastajaid \\
\hline tundmatute sõnade suur hulk & $79 \%$ \\
\hline kirjalik eneseväljendus & $77 \%$ \\
\hline õpikutekstide ja muu uue materjali lugemine & $70 \%$ \\
\hline vestlemine, diskussioonis kaasarääkimine & $64 \%$ \\
\hline ettekannete tegemine & $57 \%$ \\
\hline õpetaja jutu mõistmine & $56 \%$ \\
\hline suhtumine eesti keeles õppimisse & $55 \%$ \\
\hline instruktsioonid & $43 \%$
\end{tabular}

Õpilasankeetide tulemused sarnanesid selles küsimuses aineõpetajate ankeeditulemustega. Enamiku aineõpetajate ja õpilaste ankeetidele vastajate arvates on õpilastel raskusi peaaegu kõigi tunnitegevustega. Mõnevõrra sõltuvad probleemid pedagoogide sõnul ka ainest, õpilaste enda eluga enam seotud ained on õppijaile paremini arusaadavad. Näiteks peavad aineõpetajad põhjuseks, miks ühiskonnaõpetuse tunnis esineb õpilastel vähem raskusi kui ajalootunnis, seda, et õpilased puutuvad ühiskonnaeluga igapäevaselt kokku. Õpilaste hinnangul on kohustuslikuna eesti keeles õpitavatest ainetest kõige raskemad geograafia (44\% õpilasi vastab, et arusaamine sellest ainest on halb või pigem halb) ning ajalugu (43\% vastab, et arusaamine sellest ainest on halb või pigem halb). ${ }^{2}$ Jõukohasemad ained on õpilaste meelest kehaline kasvatus, muusika-, kunsti- ja inimeseõpetus (üle 70\% vastanutest hindas arusaamist heaks või pigem heaks).

Ka fookusgrupid tõid esile õpilaste mure selle pärast, et põhikoolist saadud eesti keele oskus on ebapiisav gümnaasiumis eestikeelse aineõppega edukaks toimetulemiseks. Ka fookusgruppides osalenud aineõpetajad rõhutasid vajadust oluliselt tõhustada eesti keele õppe metoodikat ja muuta selleks ka eesti keele ainekava (vt keeleõpetajate arvamust õpilaste keeleoskusest ja keeleõppe tõhustamisest jaotises 3.1). Siinse artikli autorite arvates on ainekavade arendus kindlasti vajalik - nii selleks, et leevendada nende ülekoormatust kui ka selleks, et paremini toetada aineõppeks vajaliku sõnavara, keelepädevuste ja õpioskuste omandamist (vt arutelu eesti keele kui teise keele ainekava üle jaotises 3.1).

2 Võimalikud vastusevariandid: hea, pigem hea, pigem halb ja halb. 


\subsection{Eestikeelsete ainetundide metoodika}

Sobilik, praktikas katsetatud ja uuringutes kinnitust leidnud metoodika aitab oluliselt kaasa õppimise motiveerivaks ja tõhusaks muutmisele. Nagu eespool mainitud, on teises keeles toimuva aineõppe puhul üheks sobivaks praktikaks LAK-õpe. LAK-õpe ei ole lihtsalt aineõpe teises keeles, vaid see on aine, keele ja õpioskuste omavahel seostatud õppimine, kusjuures peatähelepanu on aine õppimisel. LAKõppe määratluse järgi peavad tunnid olema aktiivsed, praktilised ja mitmekesised ning keelt õpitakse peamiselt selle kasutuse käigus. LAKõppe õpetaja peab valdama nii tänapäevaseid aktiivõppemeetodeid kui ka oskama anda keeletuge ja õpetada keelelisi osaoskusi (vt Mehisto jt 2010). Järgnevalt vaatleme eestikeelsetes ainetundides kasutatavat metoodikat üldiselt ning pöörame eraldi tähelepanu keeleõppe komponendile ainetunnis.

\subsubsection{Traditsioonilised õppemeetodid}

Kooliõpetuses on kaua olnud kasutusel nn traditsioonilised meetodid, mida iseloomustab õpetaja keskne roll, õpilastele valmisteadmiste esitamine ning teadmiste omandamise kontrollimine. Traditsiooniliste meetodite järgi toimuvas tunnis räägib peamiselt õpetaja, õpilased konspekteerivad, loevad õpikut, täidavad töövihikut, vastavad õpetaja küsimustele (Krull 2000). Traditsioonilistel meetoditel on oma koht ka LAK-õppes, st sealgi räägib osa aega õpetaja ning loetakse õppetekste ja vastatakse õpetaja küsimustele (Mehisto jt 2010: 38, 87). Kuid isegi hästi kasutatuna ei tohiks traditsioonilised meetodid tunnis domineerida, sest see toob kaasa ohu, et õpilased omandavad teadmisi passiivselt ja inertselt ega suuda neid koolivälisesse ellu üle kanda. Suur osa olulisi pädevusi nagu suhtlemisoskus ja koostööoskus jääb ainult traditsioonilisi meetodeid kasutades arendamata - see on laiem probleem, mis puudutab nii teiskeelseid kui emakeelseid ainetunde. Teiskeelne õpe toob selle probleemi eriti teravalt esile: ainult traditsioonilisi meetodeid kasutades on õppetöö paljudele õpilastele liiga raske, nende eesti keele oskus areneb ebapiisavalt ning aine omandamine on pärsitud.

Peamise osa LAK-õppe tunnist peaksid moodustama aktiivõppemetoodikal põhinevad tegevused nagu paaris- ja rühmatööd, rollimängud, projektid, õppekäigud, loomingulised ülesanded jmt (vt Mehisto jt 2010: 56-77). Teiskeelsetes ainetundides on eriti oluline, et õppijad saaksid uut materjali eri viisidel tunnetada ja harjutada, sest see 
kergendab nii aine kui ka keele omandamist ning komplekssete pädevuste õppimist (Aher ja Kala 1996 ja Salumaa jt 2004, 2006). Keeleõppe ekspert Hiie Asser toob välja aktiivõppemeetodite rolli õppe sisukaks ja motiveerivaks muutmisel:

Õppijatele tuleb luua mitmesuguseid võimalusi keelt kasutada ehk suhelda nii suulises kui ka kirjalikus vormis. Kui õppijatel tekib soov, sisemine vajadus oma mõtteid avaldada, selgitada, kõrvutada, kaitsta, ainult siis hajub ahistav kunstlikkuse tunne ja tekib parem arusaamine, et uus keel on lisavõimalus oma maailma avardamiseks. (Asser, Haridus- ja Teadusministeeriumi koduleht)

Tabelis 3 on esitatud meie uuringus kogutud andmed eestikeelsetes ainetundides kasutatavate traditsiooniliste õppemeetodite osakaalu kohta. Eraldi on välja toodud aineõpetajate endi arvamused (ankeedile vastajad, kes kasutavad nimetatud meetodit enda hinnangul sageli) ning tunnivaatluste andmed (tundide arv, milles meetod esines).

Tabel 3. Traditsiooniliste meetodite kasutamine eestikeelses ainetunnis

\begin{tabular}{l|c|c} 
Tegevus & $\begin{array}{c}\text { Ankeedi- } \\
\text { vastused }\end{array}$ & $\begin{array}{c}\text { Tunnivaatlused } \\
\text { (kokku 36 tundi) }\end{array}$ \\
\hline $\begin{array}{l}\text { PowerPointi slaidiesitlus (kuna on } \\
\begin{array}{l}\text { oppetaja ettekantud, sarnaneb see } \\
\text { oppetaja monoloogiga) }\end{array}\end{array}$ & $71 \%$ & $20(56 \%)$ \\
\hline oppetaja juhitud diskussioon terves klassis & $67 \%$ & $22(61 \%)$ \\
\hline töövihiku, töölehtede täitmine & $64 \%$ & $14(39 \%)$ \\
\hline õpetaja monoloog (loeng, esitlus, selgitus) & $59 \%$ & $25(69 \%)$ \\
\hline konspekteerimine & $51 \%$ & $20(56 \%)$ \\
\hline õpiku jt tekstide lugemine & $41 \%$ & $17(47 \%)$
\end{tabular}

Võrdlusena leidsid õpilased, et väga palju tehakse eestikeelsetes ainetundides kirjutamisülesandeid (80\% õpilaste arvates tihti või pigem tihti), loetakse tekste kõvasti ette (üks õpilane loeb korraga - 67\% arvates tihti või pigem tihti) ning lihtsalt loetakse õpikutekste vm uut materjali (66\% arvates tihti või pigem tihti). Seega võib nii õpilaste ja õpetajate endi hinnangute kui ka vaatlustulemuste põhjal öelda, et eestieelsetes ainetundides kasutatakse rohkelt traditsioonilisi meetodeid. Paljudes tundides domineerib õpetaja, kes esitab uut materjali ja kont- 
rollib eelnevalt õpitut, vesteldes kogu klassiga. Uue materjali esitamisel on levinud PowerPointi slaidiesitlused, mille abil õpetajad püüavad keerukat õpikumaterjali õpilastele arusaadavamaks teha. Vaatamata tänapäevasele vormile on see meetod vaadeldud tundides siiski pigem traditsiooniline - õpetaja räägib ja näitab slaide ning esitab tervele klassile küsimusi. Õpilased kirjutavad teksti slaididelt maha ja mõned aktiivsemad vastavad õpetaja küsimustele.

\subsubsection{Aktiivõppemeetodid}

On positiivne, et enamik õpetajaid püüab esitada ka küsimusi, mis arendavad kõrgema taseme mõtlemisoskust, sh kriitilise mõtlemise oskust (nt miks- ja kuidas-küsimused). ${ }^{3}$ Üldjuhul ei tekkinud vaadeldud tundides aga aktiivset arutelu, kuigi õpetaja püüdis õpilasi julgustada ja rääkima õhutada. Õpilaste passiivsuse põhjuseks võis vaatleja hinnangul olla nii ülesande keerukus, õpilaste nõrk eesti keele oskus kui ka harjumatus seda laadi aruteludes osaleda (kui see ei ole tavalises, ilma vaatlejata tunnis sage tegevus). Silmatorkavalt vähe esines tundides juhuseid, kus õpilased omaalgatuslikult midagi küsisid. Vaadeldud tundide seas olid siiski ka mõned sellised, milles õpetaja haaras suure klassitäie õpilasi oskuslikult elulisse ja eakohasesse arutellu, mille käigus õpilased esitasid ise küsimusi ja tegid järeldusi. Järgnev tabel illustreerib aktiivõppe tegevuste osakaalu uuritud koolides.

Tabel 4. Aktiivõppemeetodite kasutamine eestikeelses ainetunnis

\begin{tabular}{l|c|c} 
Õppetegevus & $\begin{array}{c}\text { Ankeedi- } \\
\text { vastused }\end{array}$ & $\begin{array}{c}\text { Tunnivaatlused } \\
\text { (kokku 36 tundi) }\end{array}$ \\
\hline rühma- või paaristöö & $74 \%$ & $9(25 \%)$ \\
\hline õppefilm, video & $45 \%$ & $3(8 \%)$ \\
\hline e-õpe & $34 \%$ & $2(6 \%)$ \\
\hline kunst, muusika, looming & $32 \%$ & $9(25 \%)$ \\
\hline ettekannete esitamine & $31 \%$ & $2(6 \%)$ \\
\hline referaat, uurimistöö & $28 \%$ & - \\
\hline rollimäng, debatt & $28 \%$ & $2(6 \%)$ \\
\hline
\end{tabular}

3 Varasemad uuringud (Mehisto 2012) on kirjeldanud mõtlemisoskust arendavate küsimuste vähesust kui üht olulist probleemi teiskeelses õppetöös. 


\begin{tabular}{l|c|c} 
Õppetegevus & $\begin{array}{c}\text { Ankeedi- } \\
\text { vastused }\end{array}$ & $\begin{array}{c}\text { Tunnivaatlused } \\
\text { (kokku 36 tundi) }\end{array}$ \\
\hline eksperimendid & $23 \%$ & - \\
\hline $\begin{array}{l}\text { õppekäik, ekskursioon jm klassiväline } \\
\text { tegevus }\end{array}$ & $20 \%$ & $1(3 \%)$ \\
\hline kirjand, essee & $17 \%$ & - \\
\hline õpiprojekt & $13 \%$ & - \\
\hline eestikeelsed külalised & $7 \%$ & -
\end{tabular}

Õpilasankeedi tulemuste järgi on aktiivsetest tunnitegevustest sage vaid ettekannete tegemine (66\% õpilaste arvates). Seega võib nii aineõpetajate ja õpilaste endi vastuste kui ka tunnivaatluste põhjal väita, et eestikeelsetes ainetundides kasutatakse aktiivõppe meetodeid liiga vähe. Isegi paaris- või rühmatööd, mis peaks esinema peaaegu igas LAK-õppe tunnis (vt tunninäiteid Mehisto jt 2010) ja mida õpetajad endi hinnangul sageli kasutavad, oli näha vaid veerandis vaadeldud tundidest. Vaid pisut alla poole õpilastest ütleb, et rühma- ja paaristööd on eestikeelsetes tundides sagedased. Kahjuks näitavad tunnivaatlused ka seda, et rühma- ja paaristööd ei kasutata alati otstarbekalt (näiteks otsivad õpilased rühmatööna konspektist faktiküsimuste vastuseid või teevad aktiivselt tööd vaid siis, kui õpetaja nende rühma juures seisab, ülejäänud ajal räägivad nad omavahel pigem muudel teemadel ja vene keeles). Teisi aktiivõppemeetodeid esines vaadeldud tundides veelgi harvem või üldse mitte. Samuti peab mitmesuguseid muid aktiivseid ja tundi mitmekesistavaid võtteid sagedaseks $6-40 \%$ õpilasankeedile vastajatest - ka kasutatavate õpetusvõtete mitmekesistamine parandaks tõenäoliselt õpitulemusi. Näiteks ütles vaid veerand õpilastest, et tunnis saavad suurema osa ajast sõna õpilased, mitte õpetaja.

Fookusgrupiintervjuudes selgus, et õpetajatel puudub selge arusaam aktiivõppe sisust. Näiteks peeti mõnikord suhtlemisoskust arendavaks meetodiks igasugust suulist vastamist, ka eelnevalt õpitud faktide kordamist. Vaadeldud tundides kaldusid õpetajad õpilaste asemel ise ära tegema ka olulise osa käsilolevast ülesandest (näiteks teksti kokkuvõtte), mida ei saa kindlasti pidada aktiivõppeks. Fookusgrupiintervjuudes väljendati veel arvamust, et aktiivõppe meetodeid saab kasutada vaid tugevamate õpilastega. Nõrgematele antakse sel juhul traditsioonilised ülesanded või lubatakse neil tunnis passiivselt osaleda. 


\section{Keeletunni tugi eestikeelsele aineõppele}

Diskussioonis vene õppekeelega koolides läbi viidava eestikeelse aineõppe üle on palju arutletud õpilaste eesti keele oskuse taseme üle: kas see on piisav, et õppida eesti keeles erinevaid õppeaineid? Nagu eelmistest peatükkidest ilmneb, on kõigi osapoolte murekohaks eelkõige küsimus, kas õpilaste aineteadmised kannatavad, kui nad õpivad oma emakeelest erinevas keeles. Siinses jaotises tuleb esmalt juttu põhikoolilõpu keeleoskuse nõuetest, keeleõpetajate arvamusest õpilaste teiskeelseks õppeks valmisoleku kohta ning tunnivaatleja tähelepanekutest õpilaste keeleoskuse ja õpiaktiivsuse kohta eesti keele tunnis. Seejärel tulevad vaatluse alla eesti keele tundides kasutusel olevad meetodid nii tänapäevased kui ka traditsioonilised ja õpetajakesksed. Jaotise lõpus vaatleme keeletunnis toimuvat ainekeele õpetust (mis on üks LAK-õppe põhikomponentidest).

\section{1. Õpilaste keeleoskusest ja eestikeelseks aineõppeks valmisolekust}

Praeguste nõuete järgi peavad põhikooli lõpetajad olema jõudnud keeleoskustasemele B1. Riikliku õppekava on järgi rahuldav õpitulemus B1.1 ehk madalam B1-tase, hea tulemus on B1.2 ehk täielik B1-tase ning väga hea õpitulemus on B2.1 (madalam B2-tase). Tasemekirjelduse järgi piirdub B1-keeleoskus lühidalt sellega, et taseme saavutanud õppija suudab end suhtluskontekstides mõistetavaks teha ja tuleb paindlikult toime igapäevaelu probleemidega (EKR 2007: 49). B1-tase on selgelt ebapiisav, et tulla teises keeles toime gümnaasiumi nõudliku õppeprogrammiga. Gümnaasiumis eestikeelse aineõppega hakkamasaamiseks oleks pigem vajalik, et kõik õppijad saavutaksid põhikooli lõpuks eakohase B2-taseme. Selle taseme saavutanu mõistab erinevate keerukate sihtkeeletekstide tuuma ja oskab paljudel teemadel luua selget, üksikasjalikku teksti (EKR 2007: 39).

Uurisime eesti keele õpetajatelt nende suhtumist praegustesse eesti keele oskuse nõuetesse. Keeleõpetajate ankeetküsitlusele vastajatest arvab $68 \%$, et õpilastele on B1-taseme saavutamine põhikooli lõpuks paras ning $80 \%$ leiab, et B2-tase oleks põhikooli lõpuks riikliku eesmärgina pigem kõrge või liiga kõrge (võrdle õpilaste ja aineõpetajate arvamusega jaotises 2.1). See näitab, et praegustes oludes ei ole eesti keele õpetajatel usku oma õpilaste suutlikkusse saavutada eestikeelseks aineõppeks vajalik tase. 
Eesti keele tundide vaatlused näitasid, et õpilaste keeleoskus on klassiti väga erinev. Peaaegu kolmandikus vaadeldud tundidest oli keeleoskustase vaatleja hinnangul selgelt liiga madal, et tunni õpitava teemaga toime tulla: õpilased ei osanud tõlkida B-tasemele omaseid sõnu ja väljendeid ega ladusalt keeleõpiku teksti lugeda ning ei saanud õpetaja küsimustest aru. Ka rääkimisoskus on vaatluste põhjal paljudes klassides üsna nõrk: õpilastel esines raskusi oma mõtete väljendamisel, küsimuste esitamisel ja küsimustele vastuste andmisel. Nagu tõime välja ka jaotises 2.1, on sellistel õpilastel väga raske toime tulla eestikeelse õppega ajaloo, geograafia jm tundides, kus teemad ja kasutusel olev sõnavara on palju keerulisemad. Keeleoskuse tase oli kõrgem vaadeldud kolmes keelekümblustaustaga klassis: õpilaste sõnavara oli suurem, keelekasutus ladusam ja rohkem julgeti ka sõna võtta.

Oluliseks keele arengu eelduseks on keeletunnis osalemise aktiivsus. Ka see oli vaadeldud tundides erinev. Umbes kahes kolmandikus tundidest oli suurem osa õpilasi aktiivses tegevuses kogu tunni jooksul. Kuid igas klassis oli rohkem või vähem õpilasi, kes tunni jooksul sõna ei saanud. Tundides ei kaldu õpilased aktiivselt oma arvamusi, seisukohti ja küsimusi esitama - seda esines vaid 6 tunnis 32-st. Enamasti reageeritakse vaid õpetaja küsimise ja töökäskude peale, oma initsiatiivi üles ei näidata.

Pooltes vaadeldud tundides kasutasid õpilased ainult eesti keelt, kuid enamasti kasutavad õpilased siiski eesti keelt vaid siis, kui õpetaja küsib - omavahel ja rühma- ning paaristööd tehes räägitakse vene keeles.

Fookusgruppides avaldasid eesti keele õpetajad valdavalt arvamust, et suurem osa õpilastest ei ole eestikeelseks aineõppeks valmis. Keeleõpetajad väljendasid pessimismi väljavaate suhtes õpilaste keeleoskust aineõppeks vajalikule tasemele viia ning ei näinud palju võimalusi, kuidas nad saaksid kaasa aidata õpilaste paremale toimetulekule eestikeelses gümnaasiumis. Osalenute arvates sõltub õpilaste valmisolek suuresti keeleõpetajast sõltumatutest teguritest: koolist, klassist ja õpilasest endast. Samas leiti ka, et keelekümblustaustaga klasside õpilased on paremini ette valmistatud.

Lahendusena eestikeelse aineõppe raskuse probleemile peeti fookusgruppides pigem tundide hulga suurendamist kui näiteks õppetöö efektiivsuse tõstmist vm. Õpetajad väljendasid arvamust, et mida varem alustada keeleõppe ja eestikeelse aineõppega, seda parem on õpilaste valmisolek eestikeelseks aineõppeks gümnaasiumis. Arvati, et juba algklassidest alates peaks olema rohkem eesti keele tunde ning et eestikeelse aineõppega tuleks järk-järgult alustada põhikoolis, eelkõige lihtsamates ainetes nagu muusikaõpetus. Kuna eesti keele kui teise 
keele tundide arv on algkoolist kuni gümnaasiumini juba praegugi väga suur, leiavad artikli autorid, et on ebatõenäoline saavutada tundide lisamise abil edaspidi oluliselt paremaid tulemusi. ${ }^{4}$ Kuna praegu põhikooli lõpetamisel nõutav B1-tasemel eesti keele oskus (mis üldjuhul ka saavutatakse; vt Lõpueksamite statistika) on eestikeelseks aineõppeks ebapiisav, tuleb oluliselt parandada õpetuse sisu ja metoodikat põhikooli eesti keele kui teise keele tundides, nii et nendel õpilastel, kes soovivad õpinguid jätkata, oleks võimalik saavutada põhikooli lõpuks eakohane B2-tase. On vaja süsteemset lähenemist, et suunata keeleõpetajaid nende rollis eestikeelse aineõppe ning õpilaste motivatsiooni toetajana.

\subsection{Eesti keele kui teise keele tundides kasutatav õppemetoodika}

Keeleõpetaja olulisim ülesanne on ehitada tund üles kindlalt eesmärgistatud tervikuna, mille jooksul õpilane omandab midagi konkreetset ja mõõdetavat. Selleks peaks õpetaja kasutama erinevaid, püstitatud eesmärki toetavaid ülesandeid ja rikkalikku keeleõppe metoodikat (Savage 1992). Õppemeetodil on väga suur mõju nii õppijate õpimotivatsioonile kui ka õpitulemustele. Tänapäevases metoodikakäsitluses domineerib kommunikatiivne lähenemine, mis on üks enimuuritud keeleõppe võttestikke ja paljudes riikides ka ametlikult soovitatud (Andon 2009: 13). Kommunikatiivses keeleõppes järgitakse järgmisi põhimõtteid: tunnis tuleb pöörata palju tähelepanu just suhtluspädevuse arendamisele - õpetaja peaks julgustama õppijaid suhtlema ja aitama neid viisil, mis motiveerib õpitut kasutama, ning suunama õppijaid ka keelekeskkonda (vt Krall jt 1997). Olulised on samuti mitmesuguste aktiivõppemeetodite (nt paaris- ja rühmatöö, rollimängud) kasutamine, õppija mõtlemis-, arutlus-, koostöö- ja õpioskuse ning iseseisvuse arendamine. Kommunikatiivses keeleõppes arendatakse võrdselt kõiki keele osaoskusi ning sõnavara- ja grammatikaõpe toetavad osaoskuste arendamist. Kommunikatiivse keeleõppe üheks rakenduseks on ülesandepõhine keeleõpe (ingl task-based language learning). Selle kohaselt peaksid õpilased keeletunnis tegelema võimalikult erinevat tüüpi ülesannetega, kus nad saavad õpitavat keelt mitmekesiselt kasutada

4 Vastavalt RÕKile on vene õppekeelega koolide eesti keele kui teise keele tundide maht algkoolist põhikooli lõpuni 30 nädalatundi ( 1 nädalatund on 35 tundi, iga tund on 45 minutit), mida näiteks prantsuse keele õpetuses peetakse piisavaks mahuks $\mathrm{C} 1$-taseme omandamiseks (vt How long will it take me to learn French?). 
(Benevide ja Valvona 2008 ja Nunan 2004). Keeletunnid peaksid olema seotud ainekeelega - kommunikatiivses keeleõppes räägitakse sel juhul sisupõhisest keeleõppest. Ka sisupõhise keeleõppe puhul integreeritakse kõiki osaoskusi, sõnavara ja grammatikat (Nunan 2004: 131).

Uuritud koolides on keeleõpet soodustavaks faktoriks see, et suur osa õpilasi peab eesti keele tunde kasulikuks (71\%) ning rohkem kui pooled ütlevad, et keeletunnid üldjoontes meeldivad neile ning et nad tunnevad, et nende keeleoskus areneb. Probleemiks on aga see, et kõigest pool õpilastest tajub eesti keele tunde huvitavana. Vaatleme järgnevalt, millised on uuritud koolides toimuva keeleõppe tugevused ja millised on need nõrkused, mis takistavad eestikeelseks aineõppeks piisava keeleoskuse saavutamist. Uurisime keeleõpetajate hinnangut 27 erineva õpetusvõtte kasutamise kohta oma tundides. Eraldi pöörasime tähelepanu tunnitegevustele, mis on abiks õppijate iseseisva õpioskuse kui ühe eestikeelse aineõppe peamise eelduse arendamisel.

\subsubsection{Keeletunni põhitegevused ja keeleõppe tasakaalustatus}

Keeletunni põhisisuks ja põhitegevuseks on osaoskuste, sõnavara ja grammatikatundmise arendamine. Tabel 5 võrdleb erinevate tegevuste kasutamist keeletundides.

Tabel 5. Põhitegevused tunnis (keeleõpetajate ankeedivastuste ja keeletundide vaatluste põhjal)

Tegevus

\begin{tabular}{l|c|c} 
& $\begin{array}{c}\text { tihti või } \text { enamasti } \\
\text { (ankeedivastused) }\end{array}$ & $\begin{array}{c}\text { tegevus esines } \\
\text { (kokku 32 tundi) }\end{array}$ \\
\hline lugemisoskuse arendamine & $88 \%$ & $19(59 \%)$ \\
\hline kuulamisoskuse arendamine & $90 \%$ & $7(22 \%)$ \\
\hline $\begin{array}{l}\text { kirjutamisoskuse arendamine, } \\
\text { sh loovkirjutamine }\end{array}$ & $86 \%$ & $12(38 \%)$ \\
\hline õpetaja poolt juhitud diskussioon & $72 \%$ & $2(6 \%)$ \\
\hline grammatika seletamine & $88 \%$ & $18(56 \%)$ \\
\hline $\begin{array}{l}\text { kommunikatiivsed grammatika- } \\
\text { harjutused }\end{array}$ & $74 \%$ & $3(9 \%)$ \\
\hline $\begin{array}{l}\text { töö sõnavaraga, sh kommunika- } \\
\text { tiivsed sõnavaraharjutused }\end{array}$ & $94 \%$ & $4(13 \%)$ \\
\end{tabular}


Õpetajad kasutavad endi sõnul kõiki tegevusi nii osaoskuste kui ka sõnavara ja grammatika arendamiseks pigem tihti ja enamasti. Tunnivaatlused seda täies ulatuses siiski ei kinnita: kuulamist, loovkirjutamist, grammatika seletamist ja kommunikatiivseid grammatikaharjutusi ning ka sõnavara arendamist oli tegelikult vähe. Samuti võib tunnivaatluste põhjal väita, et üheks õpilaste keeleoskuse arengu takistajaks on see, et osaoskuste arendamine on tihti tasakaalust väljas (domineeris lugemine) ning ka see, et kasutatav ülesandetüüpide valik ei ole piisavalt mitmekesine. Lisaks on õppeefektiivsus praegu pärsitud sellest, et õppekomponendid ei ole omavahel lõimitud: sõnavara- ja grammatikaõpe ei toeta osaoskuste arendamist. Laialt levinud probleemiks on see, et ülesannete lahendamiseks vajalikud töökäsud ei ole õpilaste jaoks täpselt ja selgelt formuleeritud. Erinevate võtete kasutamise osas lähevad seega õpetajate ankeedivastused ja keeletundides nähtu paljuski lahku. Kuigi õpetajad väidavad, et nad kasutavad pigem tihti või tihti erinevaid võtteid, näitasid tunnivaatlused, et rikkalikku keeleõppe võttestikku paljudes tundides ei olnud või kasutati seda ebaefektiivselt.

\subsubsection{Aktiivõpe ja muud tänapäevased õpimeetodid}

Kuigi aktiivõppe ja kommunikatiivse keeleõppe kasutamine on efektiivse keeleomandamise seisukohast möödapääsmatu, näitavad koolidest kogutud andmed, et just see õppetöö komponent kipub osa õpetajate tundidest puuduma. Tabelis 6 võrreldakse keeleõpetajate ankeedi ja tunnivaatluste tulemusi tänapäevaste keeleõpetusvõtete kasutamise osas.

Tabel 6. Aktiivõppemeetodid eesti keele tunnis

\begin{tabular}{l|c|c} 
Meetod & $\begin{array}{c}\text { Õpetajad, kes } \\
\text { kasutavad seda } \\
\text { tegevust enda sõnul } \\
\text { pigem tihti ja enamasti }\end{array}$ & $\begin{array}{c}\text { Vaadeldud tun- } \\
\text { dide arv, milles } \\
\text { tegevus esines } \\
\text { (kokku 32 tundi) }\end{array}$ \\
\hline rühma- ja paaristöö & $86 \%$ & $18(56 \%)$ \\
\hline rollimäng ja debatt & $62 \%$ & $1(3 \%)$ \\
\hline PowerPointi slaidiesitlus & $40 \%$ & $4(13 \%)$ \\
\hline keelekeskkonna ülesanded & $39 \%$ & $1(3 \%)$ \\
\hline e-õpe & $25 \%$ & - \\
\hline referaat ja uurimistöö & $19 \%$ & $1(3 \%)$ \\
\hline oppiprojekt & $12 \%$ & - \\
\hline eestikeelsed külalised tunnis & $6 \%$ & -
\end{tabular}


Õppurid tunnistasid fookusgrupiintervjuudel, et aktiivõppemeetodite järgi tehtavad tegevused on tõesti huvitavad ja haaravad neid kaasa. Pooled õpilasankeedile vastajatest leidsid, et enamik aega eesti keele tunnist räägivad õpilased, mitte õpetaja. Seda võib lugeda üsna heaks tulemuseks. Aktiivõppemeetoditest kasutatakse eesti keele tunnis enim rühma- ja paaristööd - seda kinnitasid nii õpilasankeetide vastused kui ka tunnivaatlused. Vaadeldud tundides viidi neid aga sageli läbi ebaefektiivselt: üksikülesannetele pühendati liiga palju aega (vahel terve tund), õpilased rääkisid rühmas omavahel vene keeles, töö esitlemisel loeti tekst maha, kusjuures domineerisid tugevamad õpilased. Kuigi õpetajad peavad tänapäevaseid õpimeetodeid väga olulisteks, kasutatakse muid selliseid võtteid vähe.

Eesti keele kui teise keele õpetajatele on pakutud suures mahus arvestataval tasemel metoodikakoolitust. Sellest hoolimata oli siinse uuringu käigus toimunud tunnivaatluste põhjal paljude õpetajate üldine metoodikatase pigem madal. Tulemused toovad esile vajaduse vaadata üle õpetajate koolitussüsteem. Tegevuste mitmekesistamine ja õpilaste aktiveerimine nõuab keeleõpetajalt palju tööd ja energiat, mida aga, nagu fookusgrupiintervjuudel ilmnes, õpetajatel napib. Keeleõpetajad kurtsid sageli oma ülekoormatust. Kõik eelmainitu on ka üheks neist põhjustest, miks õpetajad tunnevad, et nad ei suuda vaatamata pingutustele oma töö tulemusi soovitud suunas mõjutada.

\subsubsection{Oppeprotsessi toetavad ja opioskusi arendavad tegevused tunnis}

Kommunikatiivses keeleõppes peetakse tähtsaks ka õppeprotsessi toetavaid tunnitegevusi, mis võimaldavad protsessi efektiivsemaks ja õppijasõbralikumaks muuta. Õppijale on oluline teada, mis eesmärgil ta midagi teeb ning mida ta tunni lõpuks paremini teab või oskab. Eesmärkide seadmine peaks olema selge, täpne ja mõõdetav. Samamoodi on vaja teha ka tunnist kokkuvõte, et õppija teaks, mida ja milleks ta õppis. See suurendab õpilaste kaasatust õppeprotsessi ning tõstab nende õpimotivatsiooni (vt Mehisto 2012: 154). Tabel 7 võrdleb kirjeldatud tegevuste lõikes anketeerimise ja tunnivaatluste tulemusi. 
Tabel 7. Õppeprotsessi toetavad ja õpioskusi arendavad tegevused keeletundides

\begin{tabular}{l|c|c} 
Tegevus & $\begin{array}{c}\text { Õpetajad, kes kasutavad } \\
\text { seda tegevust enda sõnul } \\
\text { pigem tihti ja enamasti } \\
\text { (ankeedivastused) }\end{array}$ & $\begin{array}{c}\text { Vaadeldud tun- } \\
\text { dide arv, milles } \\
\text { tegevus esines } \\
\text { (kokku 32 tundi) }\end{array}$ \\
\hline tunni eesmärkide sõnastamine & $59 \%$ & $2(6 \%)$ \\
\hline $\begin{array}{l}\text { oodatavate õpitulemuste } \\
\text { sõnastamine }\end{array}$ & $83 \%$ & $2(6 \%)$ \\
\hline $\begin{array}{l}\text { tunni lõpus õpitust } \\
\text { kokkuvõtte tegemine }\end{array}$ & $79 \%$ & $6(19 \%)$ \\
\hline $\begin{array}{l}\text { õpilaste seniste teadmiste ja } \\
\text { kogemuste väljaselgitamine }\end{array}$ & $72 \%$ & $5(16 \%)$
\end{tabular}

Keeleõpetajad väidavad ankeedivastustes, et kasutavad õppeprotsessi toetavaid ja õpioskusi arendavaid tegevusi tunnis pigem tihti ja enamasti. Võrdluseks leidis vaid veerand õpilasankeedile vastanutest, et keeletundides tegeldakse pigem tihti või enamasti ühiselt eesmärkide seadmisega, tunni lõpus kokkuvõtete tegemise ning õpilaste teadmiste ja oskuste arengu analüüsiga. Ka tunnivaatlused näitasid, et õppeprotsessi toetavaid tegevusi ei kasutata peaaegu üldse. Osalt võib olla selle põhjuseks õpetajate õppeprotsessi toetamise meetodite liigvähene tundmine näiteks arvavad paljud õpetajad ekslikult, et vaid tunni teema tahvlile kirjutamine ja tunni tegevuste loetlemine tähendabki eesmärgi ja õpitulemuste sõnastamist.

\subsubsection{Traditsioonilised tegevused tunnis: opetaja- ja ainekesksed õpimeetodid}

Kõige sagedasemaks traditsiooniliseks tegevuseks on keeleõpetajate ankeeditulemuste järgi töövihiku ja töölehtede täitmine - pigem tihti ja enamasti kasutab seda $87 \%$. Teisi traditsioonilisi meetodeid ütlevad õpetajad end vähe kasutavat: näiteks õpiku vm tekstide tõlkimist peab oma tundides harvaks või pigem harvaks $61 \%$, konspekteerimist $88 \%$ ning õpetaja monoloogi $72 \%$ ankeedile vastanud keeleõpetajatest. Neid tulemusi kinnitasid ka tunnivaatlused. Õpilasankeedid lisavad sagedaste tegevuste sekka ka passiivsemat sorti lugemistegevused: õpikutekstide jm uue materjali lugemise ning kõvasti ette lugemise (üks õpilane loeb 
korraga; kumbagi $73 \%$ arvates). Viimase kõrval annaks aga paremaid tulemusi funktsionaalne lugemine, mis arendab õpilaste oskust kasutada kirjalikku teavet igapäevaelu situatsioonides ning mida tähtsustavad näiteks ülemaailmse PISA testi korraldajad (vt lähemalt PISA 2012: 68).

\subsection{5. Õpilaste abistamise võtted keeletunnis}

Õpilaste edasimineku tagamiseks on väga oluline see, et õpetaja oskaks õigel momendil õpilast õppetöös aidata. Vajaduse korral tuleb anda lisaselgitusi ja õpilasi küsimuste tekkimise korral nõustada. Ankeedile vastanud keeleõpetajad ise arvavad, et kasutavad piisavalt vahendeid, et õpilast keeleõppes aidata: $80 \%$ vastajatest tõi välja vähemalt kaheksa eri keelelist toetusvõtet (sh tundmatute sõnade mõista aitamine, öeldu ülekordamine jne), samas peab kaks kolmandikku õpilasankeedile vastajatest eesti keelt siiski raskeks või pigem raskeks tunniks. Seda tulemust mõjutavad ka õppematerjalid, mida eriti keeleõpetajad peavad liiga raskeks, vt järgmine jaotis.

Tunnivaatlustest ilmnes, et enamasti valitses keeletundides pingevaba ja sõbralik õhkkond. Mõnes tunnis oli seda siiski raske hinnata, sest tervet tundi täitis iseseisev töö, mille ajal ei räägitud peaaegu üldse. Tunnivaatluste põhjal on tugi õpilastele teatud määral olemas, õpetajatel jääb vaid puudu mõnest metoodilisest oskusest. Näiteks nii keelekui aineõpetajate fookusgrupiintervjuudel ja keeleõpetajate ankeetides kurdeti sageli probleemide üle, mida põhjustab õpilaste napp sõnavara. Tunnivaatlused näitasid, et keeleõpetajatel jääb vajaka oskustest sõnu selgitada, aidata uute ja tundmatute sõnade tähendust konteksti toel mõista ning õpetada sõnavara õppimise võtteid - õpetajad eelistavad sõnu pigem lihtsalt ära tõlkida või lasevad õpilastel tähendust sõnaraamatust otsida.

\subsection{Eesti keele õppematerjalid}

Õppematerjalidel on keeleõppes väga oluline koht. Hea õppematerjal motiveerib keelt õppima ning kasutama. Tänapäevased õppematerjalid peaksid põhinema kommunikatiivsel meetodil ning sisaldama õpieesmärkidega selgelt joondatud ülesandeid, mis võimaldaksid õpilastel võrdselt arendada kõiki osaoskusi. Õppematerjalid peaksid sisaldama osaoskuste arengut toetavat sõnavaraõpet ning K2 eripärasid arvestavat funktsionaalse lugemise ja kirjutamise õpet. 
Keeleõpetajate fookusgrupiintervjuudel pidasid õpetajad efektiivse keeleõppe üheks teguriks just häid õppematerjale. Õppematerjalid on aga eesti keele kui teise keele õpetamisel valukohaks. Kuigi 59\% keeleõpetajate ankeetküsitlusele vastajatest ütles, et nad on olemasolevate õpikutega rahul, väljendati fookusgrupiintervjuude süvaaruteludes nende suhtes suurt rahulolematust. Õpetajad on kriitilised, sest nad leiavad, et gümnaasiumi eesti keele kui teise keele õpikud ei ole vastavuses ainekavaga ega toeta (mitme õpetaja sõnul lausa pooles ulatuses) seda, mida õpilased tegelikult vajaksid. Ka kolmandik õpilasi ei pea eesti keele õppematerjale kasulikuks ning ligi $60 \%$ ei pea neid huvitavaks. Samas on tunnivaatluste põhjal õpikutekstide ja uue materjali lugemine eesti keele tunnis üheks sagedasemaks õppetegevuseks. Artikli autorite arvates on ühelt poolt suur vajadus uute, tänapäevast metoodikat arvestavate materjalide järele, kuid teisalt on vaja arendada õpetajate oskust teha olemasolevate materjalide seast otstarbekaid valikuid.

\subsection{Ainealase keele õpe}

Kuna eestikeelne aineõpe on õpilastele suureks väljakutseks ja nende hariduse kvaliteet sõltub paljuski keelelisest toimetulekust, on vaja leida võimalusi, kuidas erinevate lõiminguvõtete abil aineõpet igakülgselt toetada. LAK-õppe mudeli järgi tuleks keeleõpetajatel panustada aineõppeks vajaliku sõnavara ja keelendite õpetamisse (Mehisto jt 2010).

Uurisime, mida on keeleõpetajad senini teinud eestikeelse aineõppe toetuseks. Uuringu eri osade kaudu saadud tulemused on siin vastuolulised. Vaid $27 \%$ ankeedile vastanud õpilastest ütleb, et keeletundides õpitakse ainetundides paralleelselt käsitletavaid teemasid. Pooled ankeedile vastanud keeleõpetajatest (52\%) väidavad, et töötavad tihti või pigem tihti erinevate õppeainete sõnavaraga, ja $43 \%$ väidavad, et töötavad tihti või pigem tihti erinevate õppeainete tekstidega (ka õpilasankeedi tulemused kinnitasid seda tulemust). Fookusgrupiintervjuudel tunnistasid keeleõpetajad aga, et suure töökoormuse tõttu nad praktiliselt ei tegele oma tundides õpilaste ettevalmistamisega eestikeelseks aineõppeks. Kuigi keele- ja aineõpetaja koostöö on väga oluline, on see praegu juhusliku iseloomuga ja pigem süsteemitu. Keeleõpetajad suhtlevad enda sõnul aineõpetajatega vähe või üldse mitte ning vaid vähesed osalejad ütlesid, et saavad vahel harva mõne aineõpetaja käest tekste ja sõnavara, mida oleks vaja keeleõppe käigus läbida. 
Fookusgrupiintervjuude nagu ka tunnivaatluste põhjal järeldub, et keeleõpetajad ei ole teadvustanud oma rolli muutumist seoses LAK-õppega. Nad ei oma selget ettekujutust, millele oleks ainekeele õpetamisel vaja keskenduda ega oska ega soovi panustada koostööle aineõpetajatega. Keeletundide toe puudumine eestikeelsele õppele tähendab aga ühe LAK-õppe metoodika (kui teiskeelse õppe efektiivsust tõstva vahendi) põhikomponendi mitterakendamist. Keeleõpetajad vajavad muutuste elluviimist toetavat keskkonda ja süsteemi, mis hõlmab nii õppekava ja õppematerjale kui ka juhtkonnapoolsete ootuste ja toe teisenemist.

\section{Kokkuvõte}

Artikkel käsitles vene õppekeelega koolides toimuvat eestikeelset aineõpet ja seda toetavat keeleõpet. Vaatluse all olid õpetajate metoodilised lähenemised õppetöös ning sellega vahetult seotud aspektid nagu eri osapoolte usk eestikeelse aineõppe mõttekusse ja õpilaste suutlikkusse vajalikul tasemel keel omandada. Kirjeldasime lühidalt ka õppetöös sagedamini esinevaid probleeme ning õppevara ja õpetajakoolituse küsimusi. Kõrvutasime keele- ja aineõpetajate ning õpilaste ankeetküsitluste tulemusi, samade rühmade fookusgrupiintervjuude tulemusi ning keele- ja ainetundide vaatluse tulemusi. Artikkel toob esile, kui oluline on niisuguste komplekssete keeleharidusnähtuste analüüsis eri andmekogumismeetodite kaudu saadud tulemuste kriitiline võrdlus.

Uuringust selgus, et eestikeelseid aineid õpetavad õpetajad usuvad eestikeelse aineõppe mõttekusse ja õpilased tajuvad, et keeletunnid ja eestikeelne aineõpe tõesti aitavad õpilastel oma keeleoskust parandada. Samas on keeleõpetajad pessimistlikud ja ei näe praeguse seisuga võimalusi, et nad suudaksid õpilastele põhikooli lõpuks tagada B2-tasemel keeleoskuse, mis oleks aga eestikeelseks aineõppeks vajalik eeltingimus. LAK-õppes on eriti oluline pakkuda õpilastele tuge keeruka teiskeelse ainesega toimetulekuks. Hoolimata õpetajate osalemisest suurel hulgal koolitustel, ei ole aktiivõppe võtted ja õppeprotsessi toetamine õppetöösse üle kandunud. Aktiivõppevõtete kasutamine on vähene, eriti aine-, aga ka keeletundides. Koolide õppetöös peaaegu puudub LAK-õppe kolmas põhikomponent - õpioskuste arendamine. 
Uuringust tuli välja, et koolides on eestikeelne aineõpe tõepoolest ellu rakendunud. Kvaliteetsete haridusprogrammide edufaktoritest jäid uuringu käigus silma hea õpikeskkond, töine ja konstruktiivne atmosfäär tunnis. Ilmnes ka koolitöötajaid ja õpilasi ühendavate ühiste eesmärkide olemasolu, kuigi puudujäägina võib siin tuua keeleõpetajate ülekoormatuse ja keskendumise pigem eesti keele eksamiks valmistumisele kui õpilaste toimetuleku toetamisele eestikeelses aineõppes. (Selle LAK-õppe komponendi parandamiseks on pigem vaja juhtimise tasandi ja süsteemi muutusi.)

Et leevendada õpilaste nõrgast keeleoskusest tulenevaid probleeme, on vaja üle vaadata ja tunduvalt tõhustada eesti keele õpetust põhikoolis ning arendada õppevara.

Isegi kui eestikeelse aineõppe rakendamisel tuleb algusfaasis ette palju raskuskohti, näitab teiste sarnaste programmide rakendamise praktika, et probleemidest on võimalik läbimõeldud süsteemse lähenemise abil üle saada. Metoodika vaatenurgast on olulised edutegurid, millele tähelepanu pööramine on eestikeelse aineõppe arenguvõimaluseks, järgmised:

- LAK-õppe programmi komponentide süsteemne arendamine ja täielikum rakendamine, mis oleks nii teoreetiliselt põhjendatud kui ka tugineks parimatele praktikatele;

- kogu õppekava õpetuse sisu veelgi selgem fokuseerimine õpilaste toimetuleku toetamisele eestikeelses aineõppes, kasutades selleks LAK-õppe põhimõtteid (nt Mehisto jt 2010);

- kooliõppekava rakendamisel tähelepanu pööramine selle huvipakkuvusele ja tähenduslikkusele õpilaste jaoks.

\section{Aadress:}

Helena Metslang

Tartu Ülikooli eesti ja üldkeeleteaduse instituut

Jakobi 2

51014 Tartu

E-mail: helena.metslang@gmail.com

Mare Kitsnik

Tallinna Ülikooli eesti keele ja kultuuri instituut

Narva mnt 25

10120 Tallinn

E-mail:marekitsnik@gmail.com 


\author{
Ingrid Krall \\ Tallinna Ülikooli eesti keele ja kultuuri instituut \\ Narva mnt 25 \\ 10120 Tallinn \\ E-mail: ingrid.krall@tlu.ee
}

\title{
Kirjandus
}

Aher, Sirje ja Ulve Kala (1996) Aktiivõppe käsiraamat. Tallinn: Avita.

Andon, Nick (2009) What roles do theory and research play in language teaching? A case study on the task-based approach in language teaching. Doktoritöö. London: King's College London.

Asser, Hiie. Sissejuhatuseks geograafia, muusikaõpetuse ja ühiskonnaõpetuse tunnikonspektidele ja töölehtedele - teises keeles õppimise ja õpetamise põhimõtted. Materjale vene õppekeelega gümnaasiumile. Haridus- ja Teadusministeeriumi koduleht. Kättesaadav aadressil <www.hm.ee/index.php?popup=download\&id=8352>. Vaadatud 18.08.2014.

Benevide, Marcos ja Chris Valvona (2008) „Task-based language teaching” (Part 2). Widgets. A task-based course in practical English. Teacher's manual. Pearson Education Asia. Kättesaadav aadressil <http://www.widgets-inc.com/home.php>. Vaadatud 18.08.2014.

Berman, Paul, Catherine Minicucci, Barry McLaughlin, Beryl Nelson ja Katrina Woodworth (1995) School reform and student diversity: Case studies of exemplary practices for English language learner sudents. Santa Cruz, CA: National Center for Research on Cultural Diversity and Second Language Learning, and B.W. Associates.

Corallo, Christopher ja Deborah H. McDonald (2002) What works with low-performing schools: A review of research. Charleston, WV: AEL, Regional Educational Laboratory, Region IV Comprehensive Center.

EKR 2007 = Euroopa keeleõppe raamdokument. Õppimine, õpetamine ja hindamine (2007) Eestindanud Pilvi Alp, Krista Kerge, Hille Pajupuu, Mai Tiits, Ülle Türk ja Kristel Weidebaum. Tartu: Haridus- ja Teadusministeerium.

Gándara, Patricia (1995) Over the ivy walls: The educational mobility of low-income chicanos. Albany: State University of New York Press.

García, Ofelia (2009) Bilingual education in the 21st century: A global perspective. Oxford: Wiley-Blackwell.

Genesee, Fred (2003) „History of the immersion program”. Keelekümbluskeskus: 3 aasta jagu saavutusi. Tallinn: Keelekümbluskeskus.

Genesee, Fred ja Kathryn Lindholm-Leary (2012) „,The education of English language learners". Teoses K. Harris, S. Graham ja T. Urdan, toim. APA handbook of educational psychology. Vol. 3. Washington DC: APA Books. 
„How long will it take me to learn French?” Alliance Francaise in Cebu. Kättesaadav aadressil <http://www.alliancefr.ph/en/how-long-will-it-take-me-to-speak-french>. Vaadatud 06.10.2014.

Integratsioonimonitooring 2011 = Lauristin, Marju, Esta Kaal, Laura Kirss, Tanja Kriger, Anu Masso, Kirsti Nurmela, Külliki Seppel, Tiit Tammaru, Maiu Uus, Peeter Vihalemm ja Triin Vihalemm 2011. Integratsioonimonitooring (2011). AS Emor, SA Poliitikauuringute Keskus Praxis ja Tartu Ülikool.

Keelekümblusprojekt. Tulemusjuhtimise meetodil baseeruv raamdokument. Kättesaadav aadressil <http://kke.innove.ee/images/failid/pdf/valikuvoimalused/241_varakk_ rbm_trykkimiseks\%20et.pdf $>$. Vaadatud 06.10.2014.

Kello, Katrin, Anu Masso ja Valeria Jakobson (2011) Uurimisprojekti "Vene laps venekeelse üldhariduskooli eestikeelses õppes” koondaruanne. Tartu: Tartu Ülikooli Haridusuuringute ja Õppekavaarenduse Keskus.

Kitsnik, Mare ja Helena Metslang (2012) Põhikooli ainetundide sõnavara. Abimaterjal oppekeelest erineva emakeelega õpilaste keeleõppeks. Tallinn: MTÜ Eesti Keele Suhtlemiskool.

Klaas-Lang, Birute, Kristiina Praakli, Anni Peedisson ja Alla Lašmanova (2014) Arvamusi ja hinnanguid riigikeele õppe korraldamise kohta vene õppekeelega koolides. Uuringu lõpparuanne. Tartu: Tartu Ülikool, Eesti keele (võõrkeelena) osakond.

Krall, Ingrid, Elle Sõrmus ja Marju Toomsalu (1997) Kommunikatiivse keeleõppe lühikursus. Tallinn: Eesti Keele Instituut.

Krull, Edgar (2000) Pedagoogilise psühholoogia käsiraamat. Tartu: Tartu Ülikooli Kirjastus.

Kukk, Airi, Leida Talts ja Maia Muldma (2009) Keelekümblejate õppekavaalased saavutused lasteaia ja I klassi lõpul. Uuringu 2. etapi aruanne. Tallinn: Tallinna Ülikool ja Haridus- ja Teadusministeerium.

Lindholm-Leary, Kathry ja Graciela Borsato (2006) „Academic achievement”. Teoses Fred Genesee, Kathryn Lindholm-Leary, William M. Saunders ja Donna Christian, toim. Educating English language learners. A synthesis of research evidence, 176222. Cambridge: Cambridge University Press.

Lõpueksamite statistika. SA Innove veebileht. Kättesaadav aadressil $<$ http://www.innove.ee/et/yldharidus/pohikooli-lopueksamid/lopueksamite-statistika> Vaadatud 06.10.2014.

Masso, Anu ja Katrin Kello (2010) Vene õppekeelega koolide valmisolek eestikeelsele gümnaasiumiõppele üleminekuks. Vene laps venekeelse üldhariduskooli eestikeelses õppes. Projekti raames 2009. aastal õpetajate ja 11. klasside õpilaste hulgas läbiviidud standardiseeritud küsitluse analüüsi tulemused. Tartu: Tartu Ülikooli Haridusuuringute ja Õppekavaarenduse Keskus.

Mehisto, Peeter (2009) Hiliskeelekümblusprogrammi jätkusuutlikkus. Tallinn. Kättesaadav aadressil <http://dspace.utlib.ee/dspace/handle/10062/40657>. Vaadatud 18.08.2014.

Mehisto, Peeter (2012) Navigating management and pedagogical complexities in bilingual education: An Estonian case study. Doktoritöö. University of London. 
Mehisto, Peeter, David Marsh, María Jesús Frigols Martín, Kai Võlli ja Hiie Asser (2010) Lõimitud aine- ja keeleõpe. Tallinn: Integratsiooni ja Migratsiooni Sihtasutus Meie Inimesed.

Metslang, Helena, Triin Kibar, Mare Kitsnik, Jevgenia Koržel, Ingrid Krall ja Anastassia Zabrodskaja (2013) Kakskeelne õpe vene õppekeelega koolis. Uuringu lõpparuanne. Tallinn: Tallinna ülikooli eesti keele ja kultuuri instituut. Kättesaadav aadressil $<$ http://www.hm.ee/sites/default/files/uuring_kakskeelne_ope_vene_oppekeelega_ koolis.pdf $>$. Vaadatud 18.08.2014.

Nunan, David (2004) Task-based language teaching. Cambridge: Cambridge University Press.

Peedisson, Anni (2012) Eestikeelse eesti kirjanduse õpihuvist vene õppekeelega koolides. Magistritöö. Tallinn: Tallinna ülikooli eesti keele ja kultuuri instituut.

PISA 2012 = Suurim rahvusvaheline õpilaste õpitulemuslikkuse uuring PISA 2012. Eesti tulemused. PISA 2012 OSCD Programme for International Student Assessment. Tallinn: SA Innove, Haridus- ja Teadusministeerium.

Rannut, Ülle (2005) Keelekeskkonna mõju vene õpilaste eesti keele omandamisele ja integratsioonile Eestis. Tallinn: Tallinna Ülikooli Kirjastus.

Rozova, Julia (2012) Vene gümnaasiumi ópilaste eesti keele õpimotivatsioon ja selle seos eestikeelsele aineõppele üleminekuga. Magistritöö. Tallinn: Tallinna Ülikooli eesti keele ja kultuuri instituut.

Salumaa, Tarmo, Mati Talvik ja Alvar Saarniit (2004) Aktiivõppe meetodid I. Tallinn: Merlecons ja Ko.

Salumaa, Tarmo, Mati Talvik ja Alvar Saarniit (2006) Aktiivõppe meetodid II. Tallinn: Merlecons ja Ko.

Sau-Ek, Kristiina, Krista Loogma ja Vaike Vainu (2011) Hilise keelekümbluse mõju. Uuringu tulemuste aruanne. Tallinn: Tallinna Ülikooli Haridusuuringute Keskus.

Sau-Ek, Kristiina, Krista Loogma ja Vaike Võõbus (2008) Keelekümbluse 2007.-2008. aasta uurimuse aruanne. Tallinn: TLÜ Haridusuuringute Keskus.

Willis, Jane (1996) A framework for task-based learning. Harlow: Longman.

Willis, Jane (2008) Six types of task for TBL teaching English. British Council ja BBC World Service. Kättesaadav aadressil <http://www.teachingenglish.org.uk>. Vaadatud 18.08.2014.

\footnotetext{
Abstract. Helena Metslang, Mare Kitsnik, and Ingrid Krall: Content and language integrated learning methodology at Russian-medium schools. Estonian secondary schools include both the majority of schools where the language of tuition is Estonian and a minority of schools where most pupils speak Russian as their mother tongue and the language of tuition is mainly Russian. In 2007-2012, upper secondary schools of Russian-medium education in Estonia shifted to teaching $60 \%$ of the curriculum in Estonian. This was aimed at supporting Russian-medium schools' graduates' better coping in society, education and labour market. The study 'Bilingual Education in Russian-medium Schools' that our research team at Tallinn University carried out in autumn
} 
2012 confirmed that the schools have implemented this change - Estonianmedium teaching is indeed taking place (as legislated) and is swiftly developing. This article describes, with a focus on methodology, some questions of effectiveness that we studied in content and language integrated learning (CLIL) lessons and supporting Estonian lessons. We discuss the situation and development perspectives of Estonian-medium CLIL in Russian schools. Theoretically, the study relies on CLIL principles and the methodologies of active learning and communicative language learning. Most of the methodological features described in this article are also important for the majority (Estonianmedium) education system. Despite the decrease of the number of students in Russian-medium schools, it is still useful to support the development of education practitioners' skills in these areas of methodology - especially considering the increasing cultural diversification of the student body at Estonian-medium schools.

Keywords: Estonian, second language, national minorities' education, language teaching methodology, content and language integrated learning 